\title{
Relations between Placental Concentrations of Chorionic Somatomammotropin (Placental Lactogen) and Growth: A Study Using the Twin Method
}

\author{
Dungan R. MagMillan ${ }^{[14]}$, Anne M. Brown, Adam P. Matheny, Jr., and Ronald S. Wilson \\ Section of Pediatric Endocrinology and Child Development Unit, Department of Pediatrics, \\ University of Louisville School of Medicine, Louisville, Kentucky, USA
}

\section{Extract}

Concentrations of chorionic somatomammotropin (HCS) in extracts of homogenized placentas from 125 viable twin pairs were determined by radioimmunoassay. The intraclass (within-pair) correlation for placental concentration of HCS (C-HCS) was 0.64 , and for total placental content of HCS (TPHCS) 0.59 , both significant at $P<0.001$. Individual differences within twin pairs were shown to be related to both fetal and postnatal growth. The co-twin method was used to assess these relations of HCS with growth variables. Twins with relatively lower C-HCS (index cases) were compared with their co-twins with relatively higher C-HCS (control subjects) and differences on growth variables were tested by $t$ test for matched pairs. Index cases had significantly lower placenta weight $(P<0.001)$, birth weight $(P<0.001)$, and birth length $(P<0.01)$. In a similar analysis, index and control cases were separated on the basis of TPHCS, a function of both C-HCS and placental weight. Again, index cases had a significantly lower birth weight, but the relation to birth length was only marginally significant $(P<0.10)$.

Somatic measurements at age 24 months were available for 27 of the pairs who had been followed longitudinally in the Louisville Twin Study. The index cases who had had lower placental C-HCS weighed less $(P<0.02)$ and were shorter $(P<0.02)$ than their co-twin control subjects at the age of 24 months. When relative placenta weights or birth weights rather than C-HCS were used to designate index and control cases, there were no clearly significant relations with 24-month measurements; when TPHCS was used, only the relation with weight was significant $(P<0.05)$.

\section{Speculation}

In this study the maternal levels of HCS are common to both members of a twin pair and are not a factor. Placental HCS concentration and total content of HCS were found to be related to birth weight, which suggests that they are valid indices of general placental function. However, the finding that length at birth and at 24 months was best predicted by HCS concentration suggests that HCS production may represent an influence independent of general placental function. 


\section{Introduction}

Chorionic somatomamotropin, or placental lactogen, is a lactogenic protein substance first isolated from the human placenta in 1961 [4], and subsequently shown to be immunologically related to pituitary growth hormone [6]. In the ensuing decade it has been established that HCS is secreted predominantly into the maternal circulation, producing alterations in maternal metabolism which are conducive to fetal growth [3].

Extensive investigation of maternal serum HCS levels in pregnancy have shown that maternal HCS levels represent a valuable index of placental function, as most clearly demonstrated by Spellacy et al. [10]. A positive relation between fetal growth and maternal HCS levels has been demonstrated in high risk pregnancies [9], but in normal pregnancy the evidence is inconsistent [2].

Since the early work of Josimovich and Atwood [5], little attention has been focused on HCS in the placenta itself and the relation between placental content of HCS and fetal growth has not been extensively studied. In a preliminary report from our own laboratories [8], placental HCS concentrations were found to be lower for small-for-date, undernourished infants than for normally grown, well nourished infants, but the differences were significant only at the level of $P=$ 0.10. Many factors, however, are known to be related to fetal growth and infant birth weight and length. Some of these factors are of genetic origin; others are related to maternal nutrition, disease, parity, adequacy of intrauterine environment, and length of gestation. The presence of these and many other interacting influences has made it difficult to demonstrate whether a relation between levels of placental HCS and fetal growth actually exists. There have been no studies relating HCS concentrations to the course of postnatal growth.

The present investigation focussed on these relations, using the twin study method to control some of the potentially confounding variables. In the twin situation the effects of the above-mentioned maternal variables are common to both twins and, in addition, there is partial to complete control of genetic influences. Most importantly for this study, there is inherent control of gestational age, and of maternal plasma HCS and the effects it may have on maternal metabolism. Specifically, this study was designed to examine the relation between placental HCS, fetal growth, newborn status, and postnatal growth of the infant.
Sample, Materials, and Methods

Through a cooperative arrangement with local hospitals during the period of this collection of data, the Louisville Twin Study was notified of all multiple births. In the nine participating hospitals, the placentas from twin births were placed in a freezer $\left(-20^{\circ}\right)$. Within $48 \mathrm{hr}$, the placentas were collected by a Twin Study staff member, transferred to a laboratory freezer, and kept at a constant temperature of $-20^{\circ}$. At the time of collecting the placentas, the staff member also completed an information sheet on the twins, checking with hospital records on the infants' measurements, Apgar scores, type of delivery, and other perinatal data.

At the time of laboratory examination, the placentas of twin pairs were thawed for $12 \mathrm{hr}$ at $4^{\circ}$. Membranes and cord were trimmed away and fused placentas were divided along the vascular equator. Each placenta or placental part was completely homogenized and an aliquot was lyophilized and subsequently stored at room temperature.

For the assay of HCS, a placental extract was obtained by a single extraction of $500 \mathrm{mg}$ dried placenta with $5 \mathrm{ml} 0.3 \mathrm{M}$ solution of potassium chloride. Although repeated extraction was found to yield an additional $10-15 \%$ recovery of HCS, consistent yields from a single extraction were obtained and total extraction was not attempted in this study.

Radioimmunoassay of HCS was performed using a double antibody method [I], with Friesen human placental lactogen used as a standard. Multiple dilution parallel-line assays were run in duplicate for each specimen and results were obtained by computer. Calculations were made to yield values for concentration of HCS per gram of dry placental weight (C-HCS) and total placental HCS (TPHCS). Because extractions of HCS from dried placentas were not total and an international standard for HCS was not available, values for placental HCS reported in this study must be considered relative and not absolute.

These procedures yielded data for both members of 125 pairs of twins, in which both infants were viable. Of these 125 pairs, 27 pairs were followed in a longitudinal study and somatic measurements were available for them at 24 months of age.

\section{Results}

In Table I, the intraclass (within-pair) correlations for the 125 twin pairs and their respective placentas or 
placental parts are presented for six measures. The values show significant $(P<0.001)$ within-pair similarity for all the variables. The magnitude of the intraclass correlations for C-HCS and TPHCS is comparable with those for birth weight, length, and head circumference. Table I also provides descriptive statistics for the complete sample of 125 pairs (250 infants).

In the next analysis, the traditional co-twin control method was employed in order to test the relation between placental HCS and newborn status. The twin pairs were first separated on the basis of C-HCS in each twin's placenta. The twins with relatively lower C-HCS (index) were compared with their co-twins with relatively higher C-HCS (control subjects). The mean placental C-HCS for the index group was $24.1 \mathrm{mg} / \mathrm{g}$, dry placental wt, and for the control group, $35.5 \mathrm{mg} / \mathrm{g}$. The differences in growth variables of the two groups were tested by $t$ test for matched pairs, and the results are shown in Table II. The index cases with lower C-HCS relative to their co-twin controls had significantly lower placental weight, birth weight, and birth length. A similar analysis, with twins separated on the basis of placental weight, revealed a strong relation between placental weight and birth weight, but the relation between placental weight and birth length was less impressive. Separation of twin pairs on the basis of TPHCS indicated that birth weight also has a strong relation with this variable, but the relation of TPHCS to birth length was of only marginal statistical significance. Differences in head circumference, although in the same direction, were not significant in any of the groupings.

The co-twin method was also used in analyzing the data for the 27 pairs who were followed longitudinally (Table III). Because of the smaller sample size, the Wilcoxon matched-pairs, signed ranks test was used. Table III shows four analyses for these subjects. First the index and control groups are delineated according to relative placental C-HCS. At 24. months of age, there was a significant difference for length and weight, with the index twins being smaller as 2 year olds, relative to their co-twin control subjects. The findings were similar but the differences less significant when index and control groups were determined on the basis of TPHCS content. When pairs were separated by either placenta weight or birth weight, there was a tendency for the index twins to be smaller at 24 months than their control twins; however, the differences in length were not statistically significant, and the weight differences only approached significance $(P$
Table I. Descriptive statistics and intraclass correlations for placental and neonatal measurements ${ }^{1}$

\begin{tabular}{lccccc}
\hline $\begin{array}{c}\text { Placental and } \\
\text { neonatal } \\
\text { measurements }\end{array}$ & Mean & sD $\begin{array}{c}\text { Mean } \\
\text { within- } \\
\text { pair } \\
\text { differ- } \\
\text { ence }\end{array}$ & $\begin{array}{c}\text { Intra- } \\
\text { class } r\end{array}$ & $P(r>0)$ \\
\hline $\begin{array}{c}\text { HCS concentra- } \\
\text { tion, mg/g, }\end{array}$ & 28.6 & 19.4 & 10.6 & 0.64 & $<0.001$ \\
$\quad$ dry wt & & & & & \\
$\begin{array}{c}\text { Placenta weight, } \\
\text { g }\end{array}$ & 322 & 75 & 61 & 0.45 & $<0.001$ \\
$\begin{array}{l}\text { Total placental } \\
\text { HCS, g }\end{array}$ & 1.8 & 1.2 & 0.8 & 0.59 & $<0.001$ \\
$\begin{array}{l}\text { Birth weight, g } \\
\text { Birth length, cm }\end{array}$ & 2,445 & 476 & 295 & 0.70 & $<0.001$ \\
$\begin{array}{l}\text { Head circumfer- } \\
\text { ence, cm }\end{array}$ & 32.4 & 2.9 & 0.2 & 0.64 & $<0.001$ \\
\hline
\end{tabular}

${ }^{1}$ HCS : Chorionic somatomammotropin.

Table II. Measurements at birth for twins with relatively lower (index) and relatively higher (control) values for C-HCS, placenta weight, and TPHCS ${ }^{1}$

\begin{tabular}{|c|c|c|c|c|c|}
\hline \multirow{2}{*}{$\begin{array}{l}\text { Pairs separated } \\
\text { on basis of }\end{array}$} & \multicolumn{2}{|c|}{ Mean } & \multirow{2}{*}{$\begin{array}{c}\text { SE of } \\
\text { differ- } \\
\text { ence; } \\
\text { corre- } \\
\text { lated } \\
\text { means }\end{array}$} & \multirow{2}{*}{$t^{2}$} & \multirow{2}{*}{$P$} \\
\hline & Index & $\begin{array}{l}\text { Control } \\
\text { subjects }\end{array}$ & & & \\
\hline \multicolumn{6}{|l|}{ C-HCS } \\
\hline Placenta weight, $\mathrm{g}$ & 311 & 334 & 6.84 & 3.43 & $<0.001$ \\
\hline Birth weight, $g$ & 2381 & 2499 & 31.78 & 3.57 & $<0.001$ \\
\hline Birth length, cm & 46.5 & 47.2 & 0,23 & 2.84 & $<0.01$ \\
\hline $\begin{array}{l}\text { Head circumfer- } \\
\text { ence, cm }\end{array}$ & 32.2 & 32.4 & 0.17 & 1.21 & NS \\
\hline \multicolumn{6}{|l|}{ Placenta weight } \\
\hline Birth weight, $g$ & 2359 & 2513 & 31.78 & 5.03 & $<0.001$ \\
\hline Birth length, cm & 46.5 & 47.1 & 0.23 & 2.29 & $<0.05$ \\
\hline $\begin{array}{l}\text { Head circumfer- } \\
\text { ence, cm }\end{array}$ & 32.2 & 32.4 & 0.17 & 1.41 & NS \\
\hline \multicolumn{6}{|l|}{ TPHCS } \\
\hline Birth weight, $g$ & 2390 & 2527 & 31.78 & 4.30 & $<0.001$ \\
\hline Birth length, cm & 46.7 & 47.1 & 0.23 & 1.84 & $<0.10$ \\
\hline $\begin{array}{l}\text { Head circumfer- } \\
\text { ence, } \mathrm{cm}\end{array}$ & 32.3 & 32.5 & 0.16 & 1.32 & NS \\
\hline
\end{tabular}

${ }^{1}$ C-HCS : Concentration of HCS (chorioric somatomammotropin); TPHCS : total placental HCS; NS : not significant.

${ }^{2}$ Two-tailed $t$ test for matched pairs.

$<0.10)$. No significant differences were found for head circumference at 24 months regardless of the variables used to designate the index and control cases.

\section{Discussion}

These findings indicate that there is a high degree of similarity in placental concentration, content, and, 
Table III. Measurements at 24 months of age for twins in longitudinal sample, with index and control twins designated by four different predictor variables: C-HCS, TPHCS, placenta weight, and birth weight ${ }^{x}$

\begin{tabular}{lccc}
\hline \multicolumn{1}{c}{ Physical measurements } & Index & Controls & $P 2$ \\
\hline & Lower & Higher & \\
Weight, kg & 11.3 & 11.9 & $<0.02$ \\
Length, cm & 84.9 & 86.0 & $<0.02$ \\
Head circumference, cm & 48.4 & 48.5 & NS \\
& Lower & Higher & \\
Teight, kg & TPHCS & TPHCS & \\
Length, cm & 11.6 & 11.9 & $<0.05$ \\
Head circumference, cm & 85.1 & 86.0 & $<0.10$ \\
& 48.5 & 48.6 & $\mathrm{NS}$ \\
& Lower & Higher & \\
placenta & placenta & \\
wet & 11.6 & 11.8 & $<0.10$ \\
Lenght, kg & 85.2 & 85.7 & $\mathrm{NS}$ \\
Head circumference, cm & 48.4 & 48.5 & $\mathrm{NS}$ \\
& Lower & Higher & \\
& birth wt & \\
Weight, kg & 11.6 & 11.9 & $<0.10$ \\
Length, cm & 85.4 & 86.1 & $\mathrm{NS}$ \\
Head circumference, cm & 48.6 & 48.5 & $\mathrm{NS}$ \\
\hline
\end{tabular}

1 C-HCS: Concentration of HCS (chorionic somatomammotropin); TPHCS : total placental HCS; NS : not significant.

${ }^{2}$ Two-tailed Wilcoxon matched pairs, signed ranks test.

presumably, production of HCS within twin pairs. The magnitude of the intraclass correlations $(0.64$ for C-HCS; 0.59 for TPHCS) are comparable to those, within the same population, for measures of stature, which are known to be under considerable genetic influence. Nevertheless, there are individual differences within most of the twin pairs and this study has shown that these differences in placental HCS concentration and in total placental content of HCS are significantly related, not only to fetal growth, but to postnatal growth as well. The growth-promoting function of HCS as postulated by Grumbach et al. [3] cannot explain the growth differences found in this study, as both twins in a pair share equally the benefits of maternal metabolic alterations induced by HCS. It is likely that these differences in placental HCS reflect differences in functioning syncytiotrophoblastic mass and thus represent an index of overall placental function sustaining fetal growth.

Birth weight is strongly related to C-HCS, TPHCS, and placental weight, perhaps most strongly to the latter, whereas birth length is more strongly related to C-HCS than to either of the other two variables. It appears then that C-HCS, TPHCS, and placental weight are significant indicators of functioning syncytiotrophoblastic mass and hence of nutrition and general growth of the fetus. There is also the suggestion that HCS production as reflected by C-HCS may have an inclependent relation to fetal linear growth. The reported presence in the fetal circulation of high levels of pituitary growth hormone [7] makes it unlikely that the growth differences observed could be the expression of a direct somatotropic effect on the fetus of HCS, a much less potent somatotropic substance than the pituitary hormone, but this possibility is intriguing.

The relation between postnatal growth variables and placental HCS in the 27 twin pairs studied longitudinally, suggests that suboptimal HCS production is associated with reduced growth potential. Diminished cell replication in the fetus is considered to be the underlying factor in decreased growth potential in fetal undernutrition associated with placental dysfunction [11]. Reduced functioning placental mass indicated by lower C-HCS and TPHCS may similarly affect cell replication and be the explanation for the postnatal growth differences observed in this study. It is important to note, however, that in these 27 twin pairs, relative placental HCS shows a stronger relation with twin size at age 24 months than does birth weight, traditionally accepted as a sensitive index of fetal nutrition. The possibility of a direct effect of HCS on fetal cell replication, although seemingly in conflict with other evidence, is worthy of continued investigation.

\section{Summary}

Chorionic somatomammotropin concentration in individual twin placentas or placental parts shows striking correlations with placental weight, birth weight, and birth length when a method of intrapair comparison in twins is utilized. Longitudinal follow-up of 27 of the 125 twin pairs initially studied shows a persisting relation of weight and length at 24 months to placental HCS concentration. Similar relations between total placental HCS content and growth variables are observed but are Iess impressive.

In view of the fact that fetal effects of HCS exerted through the maternal circulation are common to both twins in a set, it must be assumed that placental HCS either provides a direct growth stimulating effect on the fetus or represents a sensitive index of general placental function and of the consequent effect on fetal growth and postnatal growth potential. 


\section{References and Noles}

1. Beck, P., PARkfr, M. L., AND DAUghadar, W. H.: Raclioimmunologic measurement of human placental lactogen in plasma by a double antibody method during normal and diabetic pregnancics. J. Clin. Endocrinol., 25: 1457 (1965).

2. Genazzani, A. R., Cocola, F., Casoli, M., Meluo, G., ScarSFlli, G., Neri, P., AND Frorfitr, P.: Human chorionic somatomammotropin radioimmunoassay in evaluation of placental function. J. Obstet. Gynaccol. Brit. Commonw., 78: 577 (1971).

3. Grumbach, M. M., Kap'an, S. L., Sciakra, J. J., and Burr, I. M.: Chorionic growth hormone-prolactin (CGP); Sccretion, disposition, biologic activity in man, and postulated function as the "growth hormone" of the second half of pregnancy. Ann. N. Y. Acad. Sci., 148: 501 (1968).

4. Itro, Y., and Hrgashi, K.: Studies on the prolactin-like substance in human placenta II. Endocrinol. Jap., $8: 279$ (1961).

5. Josimivich, J. B., AND ATwoon, B. L.: Human placental lactogen (HPL), a trophoblastic hormone synergizing with chorionic gonadotropin and potentiating the anabolic effects of pituitary growth hormone. Amer. J. Olsstet. Gynecol., SS: 867 (1964).

6. Josmovich, J. B., And MacLaren, J. A.: Presence in the human placenta and term serum of a highly lactogenic substance immunologically related to pituitary growth hormone. Endocrinology, 71: 209 (1962).

7. Kaplan, S. L., Grumbach, M. M., and Shepard, T. H.: The ontogenesis of human fetal hormones. I. Growth hormone and insulin. J. Clin. Invest., 51: 3080 (1972).
8. MacMillan, D. R.: Endocrine influences on fetal growth. Pediat. Clin. N. Amer., 17: 111 (1970).

9. Saxena, B. N., Emerson, K., and Selenkow, H. A.: Serum placental lactogen (HPL) levels as an inclex of placental function. New Engl. J. Med., 281: 225 (1969).

10. Spellacy, W. N., Teoh, E. S., Buhi, W. C., Brrk, S. A., AND MCCREARY, S. A.: Value of human chorionic somatomammotropin in managing high-risk pregnancics. Amer. J. Obstet. Gynccol., 109: 588 (1971).

11. WINICK, M.: Cellular growth of the placenta as an indicator of abnormal fetal growth. In: K. Adamsons: Diagnosis and Treatment of Fetal Disorders, p. 83. (Springer-Verlag, New York, 1968).

12. The authors thank Dr. H. Friesen, Royal Victoria Hospital, Montreal, for supplies of placental lactogen (chorionic somatomammotropin); Dr. M. Grumbach for encouragement and advice; R. Hawkins for technical assistance; K. Scott for computer programming; M. Hinkle for placenta collection; and the administrative and nursing stafls of the participating hospitals: Kentucky Baptist, Louisville General, MethodistEvangelical, Norton, Red Cross, St. Anthony, St. Joscphs, Sts. Mary and Elizabeth, and Salvation Army.

13. This research was supported by Grant no. HD 02372 , to D. R. MacMillan, principal investigator; by Grant no. HD 03217 to R. S. Wilson, principal investigator; The Grant Foundation; and by the Courier-Journal and Louisville Times Foundation.

14. Requests for reprints should be addresseed to: DUNCAN R. MACMILLAN, M.D., University of Louisville Health Sciences Center, P.O. Box 1055, Louisville, Ky., 40201 (USA).

15. Accepted for publication April 2, 1973. 